\title{
Welcome to the first printed issue of the Journal of Hematopathology
}

\section{J. Han van Krieken}

Published online: 19 August 2008

(C) Springer-Verlag 2008

Dear Readers,

Here you find the second issue of the Journal of Hematopathology, printed on the occasion of the Bordeaux Congress of the European Association for Haematopathology. This issue contains not only a new interesting set of publications, but also the abstracts of both the Lymphoma and the Bone marrow symposium. I hope that this journal serves you well as pathologist interested in hematopathology.

The Journal of Hematopathology was launched July 2008 and listing in PubMed was applied for. Given the requirements for that, listing is expected in the second half of 2008. For many authors also an impact factor is of importance, and although the Journal of Hematopathology does not have a high impact factor as its main aim, listing in ISI will take about 1 year.

The journal is an open access and free journal for now, and I hope that many of you will find your way to it, not only as readers but also as potential authors.

The next issue of the journal is expected later this year and will contain reviews on the new WHO classification and, hopefully, interesting new papers.

Dear colleagues, I wish you all a very interesting meeting in Bordeaux, and for those who do not attend, a very nice reading of the main new findings there!

Han van Krieken

Editor-in-Chief
J. H. van Krieken $(\bowtie)$

Department of Pathology, Nijmegen Medical Centre, Radboud University, P.O. Box 9101, 6500 HB Nijmegen, The Netherlands e-mail: J.vanKrieken@pathol.umcn.nl 